\title{
La mecánica realista frente al descubrimiento romántico en España (1873) de Edmundo de Amicis
}

\author{
Javier LÓPEZ QUINTÁNS \\ IES «Ramón María Aller Ulloa» \\ javierlopezquintans@yahoo.es
}

\begin{abstract}
RESUMEN
Numerosos viajeros italianos llegaron a España. El más singular es Edmundo de Amicis, el cual parte de Turín para descubrir la península. En este momento, un italiano, Amadeo de Saboya, ocupa el trono español. Se analizan los lugares que visita Amicis: Zaragoza y el monasterio de Montserrat, el Coso, la basílica del Pilar, la Torre Nueva; con Burgos, la catedral, el monumento al Cid, la plaza mayor; Valladolid, los ambientes catedralicios, el museo de pintura; la Puerta del Sol madrileña, el museo del Prado o la armería, o el cercano monasterio del Escorial; San Juan de los Reyes, el alcázar o Santa María la Blanca en Toledo; el Alcázar o la Biblioteca colombina en Sevilla. El trabajo estudia las fuentes románticas del texto de Amicis (Novalis, Schiller), los procedimientos realistas y la importancia del arte en el texto. Se apuntan también las concomitancias de esta obra con la de los más importantes viajeros italianos del siglo XIX.
\end{abstract}

Palabras clave: Amicis, viaje, Romanticismo, Realismo.

\begin{abstract}
Many Italian travelers arrived to Spain. Edmundo de Amicis is an unique example, which begins in Turin to discover the peninsula. At this time, an Italian, Amadeo of Savoy, took the Spanish throne. It analyzes the places Amicis visits: Zaragoza and the monastery of Montserrat, the Coso, the Basílica del Pilar, the Torre Nueva; with Burgos, the Cathedral, the monument of the Cid, the main square; Valladolid, the cathedral, the museum paint; the Puerta del Sol in Madrid, the Prado Museum or the armory, or the nearby monastery of the Escorial; the Alcázar and Santa María la Blanca in Toledo; the Alcazar in Seville and the Columbian Library. The paper examines the sources of Amicis' romantic text (Novalis, Schiller), realistic procedures and the importance of art in the text. It also points the concomitants of this work to that of the most important nineteenth-century Italian travelers.
\end{abstract} Key words: Amicis, travel, Romanticism, Realism.

SUMARIO: 1. Búsqueda geográfica e impronta sentimental. 2. Primacía del Arte. 
El sentimiento iniciático del descubrimiento de lo ajeno se mantiene como nota dominante en los relatos de viajes. Los primeros viajeros, cubiertos de una máscara de aparente inocencia, albergaban en sus intenciones más íntimas un afán de encuentro con los elementos que habían heredado de la imaginería popular acerca de la región que visitaban. Los viajes por España, en una configuración única, se revisten en gran medida del poso de lo folclórico: una mezcolanza de tópica descripción y acercamiento sesgado por los precedentes adquiere inevitable protagonismo ${ }^{1}$.

El siglo XIX acoge ilustres incursiones (las de Laborde, Mérimee, Dumas, Davillier, Doré, Borrow o Humboldt). Numerosos viajeros italianos se acercaron a nuestras tierras: Antonio Conca, Adolfo Foresta, Luigi Serristori, Elena Mario, Gustavo Strafforello o Cesare Imperiale. Edmundo de Amicis, peculiar en diversas dimensiones, parte de Turín en 1872 para descubrir España. Lo hace en el momento en que una joven Italia tiembla sobre cimientos inestables, deseosa de revestirse de símbolos y referentes que cuajen en su inexperto estado. En este contexto un italiano mira hacia una nación de añejas raíces, depauperada en el sentimiento nacional que se pierde en múltiples, ruinosas y beligerantes facciones en escisión irreconciliable y conspiratoria. Bajo este entorno, otro italiano, Amadeo de Saboya, ocupa el trono español (1870-1873), mientras miles de miradas recelosas dificultan el tránsito de un nacimiento de por sí accidentado.

Amicis parte en búsqueda de la España que adormece en sus más íntimos pensamientos, sin que ello lo haga desproveerse del proceso de extrañamiento necesario en el viaje. El individuo en tránsito padece el enfrentamiento entre la construcción conceptual de su medio y la ideología y mitemas del entorno receptor. El camino de Amicis ocupa los derroteros de un sentimiento todavía propio del Romanticismo, cocido en una revulsiva mezcla de un misticismo popular, un exotismo pintoresquista y una melancolía descriptiva que de inmediato conduce al sentido de separación y añoranza con la madre patria. El personaje romántico evidencia bajo el temperamento febril una lánguida inoperancia (Grimme, 1947), en desconexión sufriente con su tiempo (Hauser, 1969) o en agónico sentimiento (Lukács, 1971). Amicis opta por configurar un estilo íntimamente personal en el que combina la aclimatación romántica con las herramientas del estilo realista. La voz del viajero italiano en España opta por el extrañamiento romántico bajo la forma en que lo entendían Coleridge y Wordsworth: el conflicto íntimo, la disociación con los coetáneos y el desarraigo de la patria obcecadamente añorada. Ahondan bajo sus directrices filosóficas en el talante del individuo enajenado con respecto al desarrollo de la voluntad («Dialogue between Demoius and Mystes» ${ }^{2}$ ),

\footnotetext{
${ }^{1}$ A. Bordonada (1995) y Carriazo Rueda (1997).

${ }^{2}$ S.M. Coleridge (1830), pp. 68 y 137.
} 
también en el fresco aroma del espíritu solitario («full of the quiet and exalted thoughts/ of loneliness gave way to empty noise» The Prelude ${ }^{3}$.

El héroe romántico se extrae de su entorno, aquejado de un desarraigo pernicioso que lo conduce hacia la sugestiva pulsión por lo nuevo. Le fascina la tierra lejana que se contradice con la cotidianidad exasperante, y el espíritu libertador lo arropa en la indagación hacia lo desconocido. Al tiempo, la separación con la patria implica el reconocimiento de su impronta, en una vorágine idealizadora que convierte en estampa idolatrada a la tierra madre. Participa Amicis del espíritu romántico alemán, a través de la adaptación que elabora el primer gran manifiesto italiano sobre la corriente, La lettera semiseria di Crisostomo (1816).

El encuentro con lo nuevo enfatiza el sentimiento de exclusión y la figura romántica confirma su postura asindética con respecto al mundo: escisión con lo propio y choque con lo ajeno. El lugar nuevo para el héroe romántico supone también la conciencia íntima de la desunión, de la falta de integración con el mundo exótico que observa en distanciamiento protector y cauteloso. Tal epifanía implica simultáneamente la ponderación de los valores de la tierra patria, y el sentimiento de melancolía constituye de ese modo la venerada muestra de respeto. Moldea Amicis este sentimiento revistiéndolo de los ecos románticos de Wordsworth en The prelude, también Poems of the Fancy y Guilt and Sorrow.

El sentimiento de melancolía del viajero romántico, por otra parte, supone un talante misántropo propio de aquel que busca un nuevo rumbo. Enfatiza en su planteamiento la egolatría del ser romántico y su agónica sensación de soledad. El solitario individuo no hace más que reafirmar su estado ante la lejanía de la patria que le sirve de referente (lejanía pactada) y la carencia de integración en el lugar que lo recibe (lejanía impuesta). No impide este proceso de extrañamiento que el viajero revista de halo mítico el lugar que visita, que al cabo acaba convirtiéndose en peculiar muestra de la lejanía cultural que se comentaba.

Con el sentimiento romántico cuaja la conquista de un universo exótico y desconocido, por el que se procura probar la ausencia total de ligazón con el referente. El sentido de la mixtificación se despliega por el recurso impenitente al halo legendario en fusión íntima con la descripción folclórica, binomio sugestivo que engalana la exposición del viaje. De esencial peso es en esta medida la paráfrasis histórica, la exposición artística, la delimitación de los usos y tendencias culturales, como el manto de lo folclórico en tanto que arropador sustento de la esencia visceral del pueblo que se visita. Con ello se permite el culto al alma de la nación, al wolkgeist.

Esta búsqueda puede acarrear el conflicto cultural, ante el choque con lo que se siente ajeno. Si el sentimiento romántico del que hace uso Amicis responde a la incursión iniciadora por el descubrimiento arrollador de lo nuevo, la descripción de

${ }^{3}$ W. Wordsworth (1852), p. 488. 
usos, lugares y detalles de la cotidianidad de lo visitado rápidamente enlaza con las topografías y técnicas realistas, a las que por procedencia contextual y proximidad cronotópica pertenece el autor. En realidad, buena parte del éxito de Amicis radicó en la juiciosa combinación de ambos temperamentos, la exaltación y apasionamiento románticos (todavía en la retina de un lector gustoso de tales inclinaciones) dosificada con las correctas dosis mediante las probetas del realismo. Dicha peculiaridad encumbró la producción de Amicis, ágil artesano que mantuvo un equilibrio en sutil mesura entre ambas estéticas para al cabo forjar la idiosincrasia única de su obra.

\section{Búsqueda geográfica e impronta sentimental}

Amicis abandona Turín con la despedida de la tierra madre y de su propia progenitora, fascinado por el pronto hallazgo de lo nuevo. Pero en su viaje hacia Génova la voz en primera persona se tiñe del sentimiento de separación y reviste de tonos literarios la descripción de su desplazamiento. El encuentro geográfico barrunta en abundantes ocasiones el simple derrotero testimonial, pues bajo la forma de un documento se limita a testimoniar los rasgos geofísicos que ante sus ojos emergen. Configura aquí gran parte de la peculiaridad de su obra como texto de filiación romántica, dado que construye con deliberada pericia la dicotomía entre el reflejo documental de datos y la extracción del sentimiento y la reflexión íntima que ellos pueden originar. La relación documental ocupa varios puntos. En ella se integra la delimitación del paisaje que surge: las fértiles tierras desde Gerona a Barcelona, la campiña aragonesa, el campo burgalés. Este procedimiento se mantiene en Recuerdos de Londres (1873), Recuerdos de París (1878) y Constantinopla (1878). Así describe su llegada, en el último texto que referimos, a Estambul: «El mar Jonio, azul e inmóvil como un lago; los lejanos montes de la Morea, bañados en luz rosácea por los primeros rayos del astro rey; el archipiélago, dorado por el sol poniente; las ruinas de Atenas, el golfo de Salónica, Lemnos, Ténedos (...)» (2).

Adopta Amicis el papel del tipógrafo que testimonia los rasgos del lugar que visita. Participa por ello del valor documental del movimiento realista, usurpando los resortes del método científico en las entrañas mismas de su relato. Lo hace en profusos pasajes optándose por la presentación anestesiada y aséptica en la que pululan calles, cafés o tertulias. Su compatriota Elena Osorio, en 1884, reproduce la técnica documental y el detalle de los rasgos del paisaje, en sugestivas coincidencias con Amicis en paisanajes y entornos (Granada, Cádiz y Valencia en modo preponderante, 30-37, 60-78). La técnica realista se reproduce además en las imágenes de Barcelona y las Ramblas, paseo arbolado en la populosa urbe; o el bullicio del Teatro del Liceo. Añadamos que las recreaciones de Amicis resuenan en sus vísceras con los ecos de las incursiones en la ciudad condal de Stendhal (Mémoires d'un touriste), pero supera a su precedente en su voluntad aséptica de retratista de la realidad que se desprende de las cadenas de los prejucios. 
Su empeño documental aparece también con Zaragoza y el monasterio de Montserrat, el Coso, la basílica del Pilar, la Torre Nueva; con Burgos, la catedral, el monumento al Cid, la plaza mayor; en Valladolid, los ambientes catedralicios, el museo de pintura; la Puerta del Sol madrileña, el museo del Prado o la armería, o el cercano monasterio del Escorial; San Juan de los Reyes, el alcázar o Santa María la Blanca en Toledo; el Alcázar o la Biblioteca colombina en Sevilla. Y en el fin del viaje, como parte imprescindible en el itinerario romántico, Málaga, Granada y Gibraltar.

Amicis procura captar la vida en transcurso y también el instante, infiltrándose en el valor documental por el que propugnaba el Realismo. En esta tónica deben ser entendidas las numeras referencias a los convulsos estados de ánimo de los españoles alrededor de la cuestión política. Carlistas, partidarios de Sagasta, demócratas, demócratas republicanos y tantos otros manifiestan su parecer en sus líneas, sin que en ningún momento el autor se posicione a favor de ninguno de ellos (21). Pese a su asunción del papel reformador que Amadeo de Saboya pretendía proyectar sobre España, mantiene al tiempo una distancia expectante y respetuosa con respecto a su compatriota, mostrando con ello la cautela necesaria ante las actitudes de los españoles. Con Amicis pulula la dama galante, el golfillo de las calles, el gitano predicador de futuros quiméricos, el galán conquistador, la bailadora andaluza, el chulapo, el torero valiente o el chiquillo vendedor de periódicos. No excluye la técnica realista cierta predisposición a una vislumbre idealizada de los usos del español, en lo que se observa el contagio del tono romántico en la imbricación personal del gusto de Amicis para disfrute de su público lector. La presentación edulcorada del tipo peninsular contradice las andanzas de otro ilustre viajero italiano, Luigi Serristori en Ricordi sulla Spagna (1857), puesto que este último presentaba vicios intolerables en la actitud hispana, desde el goce en la inactividad, hasta la dejadez, las carencias en el espíritu emprendedor y el atraso generalizado en sus obras y proyectos (85-90, 110-125). Elena Mario, que en pasajes y asuntos parece deudora con Amicis, igualmente en 1884 desentona con la intención de su predecesor y se mantiene en la semblanza de la holgazanería del ciudadano español.

En la presentación tópica de Amicis los españoles se delimitan en actitudes generosas y campechanas, en la expansión empatizante que parece la proyección de la imagen extranjera a partir del andaluz y ampliada al resto de peninsulares. Incurre en ocasiones en la visión tópica, entendida esta como la fosilización de los patrones de conducta a partir de lo que legaron los viajeros románticos (Gauthier, Byron, Dumas) $)^{4}$, a ratos en sesgada andanza. En tal proceder pulula la siesta (parte indisociable de las rutinas peninsulares), o el Madrid de «confuso movimiento de corridas de toros, de fiestas militares, de máscaras, de bailes» (84). El ruidoso y

${ }^{4}$ A. Farinelli (1889) y J. García Mercadal (1999). 
descompasado fluir de las mareas humanas en la calles españolas confunde campesinos, obreros, damas, toreros y celestinas en caótica comparecencia. La aparición de los gitanos merece un dilatado comentario, en el que figuran sus rasgos físicos y sus costumbres (en estampas que repiten los viajeros italianos). Como ya hizo el nómada romántico, se detiene Amicis en su condición de parias y en su exclusión social, siendo el cuadro de España referente de lo que dice Croce en Cuaderno de Viaje en la Península Ibérica (1885).

La antropológica exploración de Amicis alcanza otros límites, pues singular es su interés por la comida: pucheros, potajes, guisos; y no menos peculiar su apreciación de que el español es de poco comer y de un beber pausado y morigerado (105). A la par, surca las modas españolas que considera, fundamentalmente, empapadas de los usos franceses. Con todo este equipaje, el autor procura captar el momento en una viveza ejemplar, con el juego del niño y las nueces, el parloteo informal y dicharachero de las criadas (50), el bullicio en las fondas y casas de huéspedes (que le interesa en abundantes ocasiones, 65, 99, 101, 244), el compadreo en los mercadillos (85), o las sesiones parlamentarias (184). Como resultaba frecuente en la literatura de viajes, aparecen numerosos registros conversacionales en los que procura dar voz a los compañeros de fatiga en su tránsito exploratorio $\mathrm{y}$, sobre todo, a los lugareños: guardianes, el paisano apasionado con la política, el portero adormilado. En íntima comunión con el valor testimonial, se recrea en diversas referencias históricas que fermentan en los paseos por el lugar y consolidan la presentación ante el lector: la toma de Zaragoza, la importancia de Felipe III en Madrid, la batalla de las Navas de Tolosa. En concreto, la figura de Amadeo de Saboya, principal vínculo con la madre patria que se añora, aflora en diversos paréntesis narrativos en los que se expone el papel del joven monarca en la convulsa España $(55,129)$.

El toque realista procura asimismo el acercamiento con la cosmovisión propia del lector. Amicis concibe su texto para el público de la joven nación italiana, y para él debe superar la posición de extrañamiento ante lo nuevo, de lejanía ante el entorno que se percibe como ajeno. El autor recurre para ello a numerosas referencias a Italia, siempre punto de comparación que sirva al lector para interpretar las nociones de lo que contempla. La visión del cementerio de Barcelona lo impulsa al símil, por estos medios, con Pompeya (18), y recurre también a Manzoni o a Prati para aquilatar la referencia literaria en próxima comunicación con las letras hispanas.

En sintonía con el costumbrismo romántico, que tanta predicación tuvo en la prensa, otorga la voz diegética un rol preponderante a la presentación de tipos, en los que se advierte una mezcla desigual del individuo con entidad y el mero prototipo aquejado de convencionalismos heredados de la tradición literaria. Observemos en confirmación de lo dicho el retrato del campesino catalán, con el traje negro, el gorro y las polainas (12). La presentación del carnaval avanza pareja con el afán costumbrista, a través de los participantes de la mascarada y la 
indumentaria de los niños, de los adultos que se metamorfosean en campesinos de antaño o en figuras dispares (gitanos, montañeses o jardineros), de las gentes que acuden al teatro de la Comedia, a los toros, o a las peleas de gallos. Igual que en la literatura de viajes sobre España ${ }^{5}$ (añadamos que el chileno Lizardi mucho debe a Amicis), el autor acude a una corrida de toros, en Madrid, el 31 de marzo. El arte de Frascuelo y Cuco, la disposición del coso, los banderilleros, el palco, configuran la presentación. La muerte del toro constituye un espectáculo dantesco, pero Amicis nos deleita igualmente con la indumentaria de los toreros, o nos aporta la curiosa presencia de toreras y banderilleras (159). Al cabo mantiene el autor una postura distanciada en la que evita valorar el espectáculo, en tímido respeto, y no aporta gran novedad en la descripción de la liturgia taurina si lo comparamos con sus precedentes. El barón Taylor en Voyage pintoresque en Espagne y las cartas a la Revue de Paris de Merimée nos facilitan cuidadosos cuadros del ritual que abraza la práctica taurina y se asientan como precursores de las imágenes literarias que más tarde nacieron sobre ello.

La abundancia de tipos del texto del viajero italiano nos ofrece una sorprendente estampa, a la altura del cuaderno costumbrista y su diversidad de figuras. A los ya aludidos, sumemos el perfil del soldado (16) y del campesino aragonés (con sus corbatas, chalecos de colores, pañuelos, 38). Íntimamente, la impronta sentimental, al modo romántico, ocupa su posición preponderante en cada línea. Amicis otorga relevancia al sentimiento amoroso como causa de conflicto íntimo y arrebatado desencuentro con el mundo. El amor arremete contra la propia contemplación del paisaje que, por tanto, se tiñe de una aureola de desencajado desencanto. En el inicio mismo del itinerario, partiendo de Turín, encuentra el viajero a un compañero de vagón que se desplaza "per amore" (8), amor que arrastra y empuja hacia los brazos extraños, fríos pero propicios del néofito entorno. Tributo de amor aparece con los disciplinantes catalanes que se azotan ante su adorada (28), y con el anhelante amor de Félix y Aurora en la balada La Pasionaria (93), así como con los jóvenes valencianos que lloran al separarse (377). Reviste de contemplación sentimental las regiones que visita; en Córdoba, «con el perfume un soplo de aire fresco, y con el aire un dulce murmullo de voces de mujer, de cantos de pájaro, de hojas arrulladoras; una armonía suave y variada que, sin turbar el silencio de la calle, recrea el oído como un eco de música lejana» (234). La visión idealizada convierte al texto de Amicis en antitética pulsión de un ilustre precedente, Luigi Serristori. No recaía este último en la rememoración poética bajo cierto deturpado filtro íntimo; su descripción ahonda en esencia en otra óptica de una Andalucía atrasada e impúdica, en la que el solaz prevalece sobre el esfuerzo (1856: 110-120). La peculiaridad de Amicis, recordemos, radica en el uso personal del sentimiento romántico para las incursiones de su literatura de viajes.

${ }^{5}$ F. Aínsa (2008). 
El impulso de la melancolía atenaza la garganta del viajero que, en peculiar descenso, ostenta un papel singular de narrador homodiegético, protagonista de su relato que reviste un incurso documental de reminiscencias literarias. Llega el frío a su corazón («las lágrimas acudieron a mis ojos», 46), y anhela Italia, sintiéndola lejana en medio de una isla de soledad. Constituye este un sentimiento que recrea profusamente Amicis: ante la visión del mar, el protagonista de Corazón experimenta el "sentimiento de su propia soledad" (207), junto con la melancolía (199) o el poso de la tristeza desde el mundo que contempla $(36,70,114,156,247)$. La exaltación del Yo, impresa con el latido exultante del Romanticismo, hermana los textos de Amicis, en una marea de emociones engalanando la percepción sobre el entorno. Ahí están la magia de París, la seducción de Granada, el hechizo de Estambul («iAh, cómo me latía el corazón! ¡Con qué fiebre en el alma aguardaba aquella bendita palabra: Adelante!», Constantinopla, 13).

«Debilidad ante el infortunio y el dolor físico. Tenemos que apresar todas las sensaciones», considera Novalis ${ }^{6}$. Bajo el magisterio de Novalis, presentemos el "corazón oprimido" (197) tras los tres meses que se citan lejos de casa, el corazón «vacío» en el final del viaje (234); la soledad (258); y las lágrimas, el cauce del desahogo, en la despedida de España (378).

Del sentimiento romántico procede la adoración por la Edad Media y sus efluvios galantes de castillos y pugnas caballerescas (205), según testimonia Heine en Die Romantische Schule (1833-1836). Procede de la mixtificación romántica la imagen de España (y más en concreto Andalucía) adornada con los ropajes de Oriente (234). Sigue en ello el empeño por el exotismo de Chateaubriand, también de Byron, o de los orientalistas Loti y Cherbonneau. En la contemplación del nuevo entorno, se rompen las fronteras de lo onírico, y el sueño se confunde en angustiosa mezcolanza con la realidad (259). El sueño es descubrimiento y reconstrucción en el canal de la fantasía reparadora, en los brazos de la manipulación ontogénica en ropajes de Novalis. La importancia de lo legendario en España enlaza con la incursión sentimental y el bosquejo melancólico. Reproduce entonces Amicis la leyenda del Papamoscas, tributo de Enrique III hacia la mujer que le entrega la vida; los amores entre Carlomagno y la hija del rey Galafro; y la leyenda de la Cava y el último rey visigótico, don Rodrigo. En el año 1873, Davillier con Voyage en Espagne, nos ofrece una concomitante visión legendaria de España, con la Cava inmersa en las desgracias del reino visigodo. Ambos (Amicis, Davillier) participan de la tradición literaria española, más en la versión popular de la historia de la hija del conde Julián que en las fuentes donde se documenta el luctuoso suceso (caso del Cancionero de Pedro del Pozo de 1547, o el de Romances de 1570).

\footnotetext{
${ }^{6}$ Novalis (2007), p. 70.
} 


\section{Primacía del Arte}

Rasgo esencial de la obra de Amicis es la incursión en los derroteros del arte; participa el autor del interés por las principales manifestaciones culturales del lugar que visita, dado que en la literatura de viajes del XIX semejaba casi canónica la presentación de las peculiaridades artísticas de la zona por la que se deambulaba. Se constituye desde muy temprano, gracias a este elemento, un doble valor, desde el prurito de erudición hasta el papel básico de guía de viaje que sirva de cicerone documental al futuro lector. El arte se convierte en interpretación del mundo, a juicio de Holderlin en Hiperión; en camino cierto hacia la verdad según postulaba Scheling (Filosofia del arte, 1802). Búsquese también en dicha noción la huella de Schiller, de Novalis o de Eichendorf.

Las líneas de Amicis nos permiten comentar diversas referencias artísticas, que empiezan desde la admiración ensimismada a la obra de Baretti en la catedral de Barcelona. Las abundantes referencias y apostillas demuestran el afán de exactitud con el que no siempre están en consonancia otros libros de viajeros por tierras de España ${ }^{7}$. En estos últimos, vagas alusiones decaen en cita fugaz que con simpleza procuran la demostración de la presencia del viajero en el lugar, sea ello con llaneza expositiva henchida de la mera elucubración subjetiva o la impresión personal. Amicis, por el contrario, ahonda en la configuración del elemento visitado, de forma que conocemos los rasgos góticos de la catedral de Barcelona y la composición arquitectónica de la misma (las tres grandes naves, el Coro o la capilla subterránea, también el claustro). La concepción hegeliana del arte como lección ahistórica, a través del vínculo expresión con contenido, es tomada en el constructo de Amicis sobre la atemporalidad de la manifestación estética. Para Amicis, con Hegel, el ente artístico se aísla de la corriente temporal en tanto entidad autónoma sujeta (inevitablemente) al recorrido del tiempo pero a la vez dotada de alma individual que alcanza una personalidad propia. Con la armazón hegeliana establece Amicis la comunicación fructífera con el objeto de arte, portador este de conocimiento y destellos de su imperecedera singularidad.

Los ejemplos se diversifican. Numerosas referencias disfruta Nuestra señora del Pilar, en un profuso pasaje que navega por los orígenes y desarrollo del edificio, por las características de su estilo y la diferenciación en sus altares (dígase el de San Jaime). La impregnación del yo (Selbstheit), en notas de Novalis, logra la estetización de la vida, empapada de la comunicación imprescindible con el arte: «¿Cómo vemos corporalmente? Igual que en la conciencia -mediante la imaginación productiva. La conciencia es ojo, oreja y sentimiento para el sentido interno y el externo -para uno mismo- porque no se compone, y tiene que componerse más que de opuestos» (Fragmentos, 182).

${ }^{7}$ F. Wolfettel (2005) y A. Gasquet (2006). 
La inclinación estética del ego borda el papel de Amicis; la armazón expositiva se reproduce en las incursiones de la peculiaridad catedralicia de Burgos, en el que los adornos del edificio (agujas, estatuas, arcos...) ostentan importancia similar a la de la distribución de sus naves y altares góticos, a las pinturas atribuidas a Leonardo da Vinci o Miguel Ángel (69). «Tenemos que comunicarnos de manera adecuada, artística, prudente» (69), afirma Novalis, precisión en la óptica en búsqueda del significado oculto de la obra. Emerge entonces el afán de alcazar el sentimiento solapado del objeto. La catedral vallisoletana, a los ojos de Amicis, nos ofrece interesantes imágenes (la tumba de Pedro Anzúrez es vehículo de impresiones inefables). Vocación de eternidad se percibe en el arte, según comulga Amicis; arte que prevalece más allá de la azarosa contigencia, constituyéndose en la Belleza en óptima constitución. Amicis participa de los principios de Eichendorff, de la insaciable pesquisa por lo eterno en la producción artística (que Eichendorff identifica con la obra de Calderón en Zur Geschichte des Dramas y Geistliche Schauspiele von Don Pedro Calderón de la Barca).

La búsqueda de lo absoluto desemboca en el mayor interés que le despiertan el Escorial, los orígenes del edificio y sus características (bóvedas, sacristía, las reliquias), la mezquita de Córdoba y la Alhambra de Granada. Cada uno por motivos diversos pero de peso similar; el arrobo místico que extrae el primero junto con el aroma oriental de los siguientes, ambos compartimentos de la inclinación romántica. La singularidad de la obra se estila bajo el filtro kantiano en la interpretación de Schiller (Cartas sobre la educación estética del hombre): la autonomía del objeto más allá de la circunstancia azarosa del momento creador. La conjunción de finitud e infinitud cuajan en la producción artística en unión íntima, retozando Amicis en el concepto schilleriano de la forma y vida en vínculo armonioso en el arte. El arte alcanza tributos, en la comunión de Amicis, de diversa índole. En estos supuestos identificamos en Granada el homenaje a los viajeros románticos: Byron, Hugo, Chateaubriand, pues de ellos proceden las digresiones sobre Comares, el Albaicín, las fuentes de la Alhambra (335).

La comunicación con el arte se produce en abundantes escalas. Numerosas son las pinturas que pululan por las páginas de España: de las extranjeras, sobresalen Rubens, Carduci, Lorrain o Tintoretto; de las españolas, Ribera, Velázquezo Murillo. La esencia de lo español se encarna en el gran Goya y su visión descarnada de la humanidad (121), y se asume con el pensamiento romántico la coronación de la obra goyesca en los vislumbres del tormento del yo. La pintura para Amicis reviste valores simbólicos y un poder sugestivo, acomodado en las percepciones de La filosofia de los colores (1810) de Philipp Otto Runge. En Amicis la luz modifica la percepción de la pintura y moldea el mensaje que subyace en el lienzo, al modo de lo que afirmaba Goethe en Esbozo de una teoría de los colores (1810) con el proceso de ponderación de la experiencia científica del arte. Teofastro, para Goethe, profundizaba en el significado del color, siendo por tanto tarea del artista moderno bucear en el metafísico significado de la obra. Amicis plantea la visión cromática 
como alma de la obra que alberga el significado profundo; y se aproxima a la tríada de colores físicos, químicos y fisiológicos de Goethe, en correcta armonía de lo que es manifestación evidente a los sentidos y conformación del proceso creador, sumado el poso del tiempo en la obra.

De otro lado, lo literario ocupa en altura justa un papel destacable. Amicis demuestra su conocimiento de la cultura hispana, en profundidad conceptual a la altura de sus debilidades por la pintura. Advertimos en sus juicios el papel reformador de Juan Boscán, el insigne responsable de la llegada de metros italianos a España (25). Suenan también Zorrilla, Lope, Espronceda, Garcilaso o Fernán Caballero. Entre ellos, Zorrilla reaparece como figura admirada, y se alude tanto a Los cantos del Trovador como al Don Juan. La referencia al Quijote se convierte en apostilla anecdótica en una persistente reiteración en la literatura de viajes, donde el tributo al magno texto hispánico parece referencia casi obligada. En la obra de Amicis se extraen numerosos pasajes de la obra cervantina como condimento adicional a las impresiones del paisaje. $(29,193,227)$.

Fundamental en el plano de las reflexiones literarias es la visita a Madrid, en la que comenta la importancia del teatro y ofrece la amplia nómina de creadores: Ayala, García Gutiérrez, Ventura... Curiosamente, analiza los males que en el ámbito de la dramaturgia percibía la crítica española: la deficiente preparación de los actores, los pobres asuntos o la convivencia de géneros de calidad dispar (sainetes, vodevil, zarzuela, comedias políticas...). La literatura extranjera, en especial la italiana, tiene asimismo cabida en sus líneas. Ocurre con la fugaz alusión a Manzoni y su Pentecoste o a Gauthier (75). También Prati en la comparación con Zorrilla, Leopardi en la delimitación del genio, Marini a la altura de Góngora en la deformación del idioma.

Importante igualmente, en una esfera lingüística, es su defensa del catalán como lengua, esgrimiéndose como criterio el peso de su tradición literaria, eclosionando por tanto con el pensamiento de la Renaixença (26). No es esta la única reflexión lingüística, pues sugestiva presencia encontramos en la página 83 y la alusión al dialecto aragonés. Amicis reflexiona sobre las peculiaridades fonológicas del español, en un moderno excurso sobre fonética y prosodia, y enumera los dialectos que conviven con él en España (valenciano, gallego, murciano, 103); incluye al catalán cuando, al principio de la obra, lo catalogaba como lengua.

El sentimiento romántico, según se ha visto, se acopla en la descripción costumbrista que realza el detalle como contemplación de la vida. Sin embargo, vida y estética, al modo de Novalis y en la esencia de Schiller, configuran el encuentro íntimo del yo con el arte. La obra de Amicis participa de la literatura de viajes y del sentimiento de desencuentro y separación que cultivaron otros ilustres viajeros. Como ellos, afronta el contacto con el nuevo entorno para deleitar al lector mediante los elementos esenciales de la región primigeniamente utópica y al fin trastocada por la deturpada visión tradicional y el empeño en el valor documental. Las relecturas sucesivas de España nos legan a un autor volcado en un estilo propio 
(el mismo de Corazón o Constantinopla), la comunión entre el sentimiento romántico y la vocación realista.

De su lado, contemplamos el arte en su aspiración universal según forjó el Romanticismo. Como el héroe romántico, la voz en primer persona sufre el desconsuelo de la soledad y la tragedia de la separación, recubriendo su nuevo entorno de exótico misticismo. Recupera además la visión orientalista de España enfocada en una guinda propiciatoria: Andalucía. Del sentimiento de Novalis, pugna por la fusión con el valor intangible de la Belleza. El valor de la obra de Amicis nos aporta la fusión de corrientes estéticas. Su mirada melancólica, en el desenlace, constituye un colofón último y esclarecedor de propósitos.

\section{Obras citadas}

AÍNSA, Fernando: «Peregrinaciones en la narrativa hispanoamericana del XIX y XX. Entre el viaje iniciático y la búsqueda de raíces», en Julio Peñate Rivero y Francisco Uzcanga Meinecke (eds.), El viaje en la literatura hispánica: de Juan Valera a Sergio Pitol, Madrid, Verbum, 2008, pp. 4764.

AMICIS, Edmundo de: España, Madrid, Vicente López, 1883.

, Corazón (diario de un niño), México, Secretaría de educación pública, 1925.

BordonAdA, A.: Literatura de viajes, Madrid, Universidad Complutense, Servicio de publicaciones, 1995.

CARrizo RUEDA, Sofía: Poética del relato de viajes, Kassel, Reichenberger, 1997.

COlERIDGe, Samuel Taylor: On the Constitution of the Church and State, New York, Classic Books Company, 1830 (edición de 2001).

FARINELLI, Arturo: Apuntes sobre viajes y viajeros por España y Portugal, Oviedo, Establecimiento Tipográfico de Adolfo Brid, 1889.

García MERCADAL, José: Viajes de extranjeros por España y Portugal: desde los tiempos más remotos hasta comienzos del siglo XX, Valladolid, Junta de Castilla y León, Consejería de Educación y Cultura, 1999.

GASQUET, Axel: «Bajo el cielo protector. Hacia una sociología de la literatura de viajes», en Manuel, Lucena Giraldo y Juan Pimentel (eds.), Diez estudios sobre literatura de viajes, Madrid, Consejo superior de investigaciones científicas, 2006, pp. 31-66.

HAUSER, Arnold: Historia social de la literatura y del arte, Madrid, Guadarrama, 1962.

LuCENA GIRALDO, Manuel y Juan Pimentel (eds.): Diez estudios sobre literatura de viajes, Madrid, Consejo superior de investigaciones científicas, 2006.

Novalis: Estudios sobre Fichte y otros escritos, Madrid, Akal, 2007

ROMERO TOBAR, Leonardo y Patricia Almarcegui (coords.): Los libros de viaje: realidad vivida y género literario, Madrid, Akal, 2005. 
WOLFETTEL, Friedrich: «Relato de viaje y estructura mítica», en Leonardo Romero Tobar y Patricia Almarcegui (coords), Los libros de viaje: realidad vivida y género literario, Madrid, Akal, 2005, pp. 10-24.

WORDSWORTH, William: Complete poetical works, Troutman anda Hayes, 1852. 